\title{
Is resting pupil size a predictor of GAIH?
}

\author{
Jinshan $\mathrm{Shi}^{1} \cdot \mathrm{Ke} \mathrm{Jiang}^{2} \cdot$ Bailong $\mathrm{Hu}^{2}$ (1) \\ Received: 16 November 2019 / Accepted: 24 January 2020 / Published online: 31 January 2020 \\ (c) Japanese Society of Anesthesiologists 2020
}

Keywords Pupil size $\cdot$ Hypotension $\cdot$ General anesthesia

To the Editor:

We have read with great interest the recently published article by Miyazaki et al. [1], which investigated whether the pupillary response can function as a predictive factor of hypotension after induction of general anesthesia (GAIH). The author showed that measurement of maximum pupil size was useful to identify patients at risk for GAIH. However, there are several aspects of this study that need to be clarified and discussed.

First and foremost, Yeniay et al. found that preoperative fasting time is one of the risk factors for GAIH and patients who fast very long are more likely to have GAIH [2]. However, the preoperative fasting times were not clearly described in the method section.

Moreover, although no cases of difficult intubation were encountered in this study, the intubation time and the intubation success rate of each patient were not described clearly in the method, which have an important effect on hemodynamic changes during anesthesia induction [3]. This may confuse the interpretation of their findings. We believe that this would help to further support the findings of this study by addressing the above issues.

Jinshan Shi and Ke Jiang contributed equally to the letter.

This comment refers to the article available online at https://doi. org/10.1007/s00540-019-02672-y.

Bailong $\mathrm{Hu}$

375896605@qq.com

1 Department of Anesthesiology, Guizhou Provincial People's Hospital, No. 83 Zhongshan East Road, Nanming District, Guiyang 550004, China

2 Department of Anesthesiology, The Affiliated Hospital of Guizhou Medical University, No. 28 Guiyi Street, Yunyan District, Guiyang 550004, China
Funding None.

\section{Compliance with ethical standards}

Conflict of interest The authors declare that they have no competing interests.

\section{References}

1. Miyazaki R, Sumie M, Kandabashi T, Yamaura K. Resting pupil size is a predictor of hypotension after induction of general anesthesia. J Anesth. 2019;33(5):594-9.

2. Yeniay O, Tekgul ZT, Okur O, Koroglu N. Unexpectedly prolonged fasting and its consequences on elderly patients undergoing spinal anesthetics. A prospective observational study. Acta Cir Bras. 2019;34(3):e201900309.

3. Xue FS, Zhang GH, Li XY, Sun HT, Li P, Li CW, Liu KP. Comparison of hemodynamic responses to orotracheal intubation with the GlideScope ${ }^{\circledR}$ videolaryngoscope and the Macintosh direct laryngoscope. J Clin Anesth. 2007;19(4):245-50.

Publisher's Note Springer Nature remains neutral with regard to jurisdictional claims in published maps and institutional affiliations. 